\title{
Telenovela: um olhar sobre a produção acadêmica
}

\section{Resumo}

$\mathrm{O}$ presente artigo pretende apontar o inicio das investigações acadêmicas que têm como tema a telenovela e demais formatos da ficção televisiva, como exercício para percepção da construção do campo de estudo nessa área.

O início da telenovela no Brasil acontece em 1951, com pequena inserção na grade de programação da televisão e ainda presa a antecedentes, como a linguagem radiofônica e a do teatro, entre outros. Foi necessário um percurso de dez anos para que sua instalação na grade de programação, de forma diária, se tomasse realidade. Portanto, em 1961, inicia-se a transmissão da telenovela diária, consolidando-se a partir daí, através dos anos como um dos produtos de maior audiência do meio televisivo. No final dessa década, apesar de restrita aos textos importados, distantes do cotidiano nacional, é que se processa a ruptura com os modelos até então vigentes na elaboração dessas obras de ficção. Em 1968, com Beto Rockfeller marca-se o início da teledramaturgia brasileira. Daqueles tempos aos atuais muita coisa mudou, mas isso seria tema para outro artigo. Neste trabalho o objetivo principal é verificar a trajetória da telenovela, quando essa forma de narrar o cotidiano passa a ser preocupação da Academia.

Falar da produção acadêmica que tem a telenovela brasileira como objeto principal de seus estudos, no século XXI, é tarefa complexa visto que são inúmeras as Universidades e linhas de sua pesquisa. Por mais cuidadoso que seja esse mapeamento, ele se mostrará sempre incompleto, principalmente levando em conta que a produção científica obedece, a cada dia, a um ritmo mais frenético ditado pela emergência das novas necessidades sociais. Isso sem contar com os diversos trabalhos em âmbito internacional, que escolhem esse produto brasileiro como objeto de investigação e muitas vezes sem seu conhecimento no Brasil. Um exemplo a respeito é o doutorado de Thomas Tufte, defendido na Inglaterra em 1990, com a tese "Living with the Rubbish", que tinha como objetivo examinar as formas de recepção da Telenovela Rainha da Sucata em três regiões do Brasil.

Será que essa produção acadêmica foi e é tão intensa? Será que a telenovela tem tanta audiência na Academia, como tem nos lares brasileiros? Será que a produção desse produto é proporcional ao que se estuda sobre ele?

O primeiro registro brasileiro conhecido da telenovela como objeto de estudo acadêmico é de 1974, com o trabalho de Sônia M. P de Barros: "Imitação da vida: pesquisa exploratória sobre a telenovela no Brasil", oriundo de uma das unidades da USP (FFLCH). Desde então surgem trabalhos diversos a respeito na Universidade de São Paulo merecendo um detalhamento ainda a ser feito.

Outra instituição que registra seu primeiro trabalho com esse tema, nessa mesma década, é a Universidade Federal do Rio de Janeiro, com uma dissertação defendida em 1975, na Escola de Comunicação, por João Luís Van Tilburg, intitulada "O estereótipo visual na telenovela brasileira como instrumento de educação permanente". Esse trabalho marca também o ingresso 
desse tema nas agendas de investigação dessa Universidade, tomando-se tema constante nos trabalhos dessa unidade e de outras que integram a instituição.

Entram em cena na década de 1980 duas instituições: a Universidade de Brasília com sua primeira produção acadêmica sobre esse tema, com a dissertação de Jane Jorge Sarques, "A ideologia sexual dos Gigantes”, defendida em 1981; e a Fundação Getúlio Vargas, com a dissertação de Icléia Rodrigues de Lima, “O projeto ideológico das telenovelas brasileiras: análise de conteúdo", defendida nesse mesmo ano.

É nessa década que se têm o ingresso de duas universidades com produção sobre esse tema:

a

Universidade Federal do Paraná com a dissertação de Elisa Rocha, "Educação sexual e telenovela: liberação sexual ou determinismo ideológico", defendida em 1987; e dois trabalhos de mestrado, nesse mesmo ano, na Universidade Metodista de Piracicaba, defendidos por Aurora Barbosa "Da narrativa literária a telenovela: o exemplo de Gabriela Cravo e Canela" e por Cezar Toledo "Romance: pedagogia e história (a produção da arte na sociedade burguesa)".

Um levantamento útil para quem deseja verificar as primeiras referências sobre trabalhos acadêmicos com esse tema é a obra "Ficção seriada na TV: as telenovelas latinoamericanas"1, que traz, a partir da página 169 , bibliografia anotada da telenovela brasileira, incluindo trabalhos produzidos no Brasil e em outros países que elegeram a telenovela brasileira com centro de seus estudos.

Importante também para quem se dedica ao estudo da telenovela é recorrer a leitura de obras como "Telenovela: história e produção"; "Dramaturgia de Televisão"; "O Carnaval das Imagens: a ficção na TV" e "A Deusa Ferida: por que a Rede Globo não é mais a campeã absoluta de audiência?".2

Outra obra de grande utilidade para os estudiosos do tema é "Memória da Telenovela Brasileira"3 que mapeia, até o ano de 1996 em sua 4a . edição, as obras de ficção veiculadas e produzidas nas emissoras-produtoras.

Além dessas obras é importante destacar a seção de bibliografia especializada sobre telenovela existente desde 1994, na revista Comunicação \& Educação ${ }^{4}$. Nessa seção encontram-se resumos de livros, artigos, teses, dissertações e monografias que têm como tema a telenovela e os demais formatos da ficção televisiva seriada. ${ }^{5}$

Com o advento da Internet e a disponibilização das obras em catálogos on line é possível, atualmente, ter contato com inúmeros trabalhos espalhados pelo Brasil e pulverizados em várias áreas do conhecimento como Educação, Antropologia, Sociologia, Comunicação, Administração etc., que tiveram como tema a telenovela. Grandes instrumentais nessas buscas além dos catálogos bibliográficos, muitos deles on line, disponibilizados por inúmeras Universidades - são os sites das instituições de fomento à pesquisa. ${ }^{6}$

A cada ano inserem-se trabalhos de instituições de ensino superior, públicas e privadas, que têm como objeto a telenovela e os demais formatos da ficção televisiva. Isso pode ser detectado em grupos de trabalhos como os da Intercom e pelo interesse crescente de pesquisadores que buscam em centros de pesquisas, como o Núcleo de Pesquisa de Telenovela NPTN da ECA-USP, apoio ou orientação para pesquisas dedicadas a esses temas.

Em breve levantamento de instituições com trabalhos sobre esse tema pode-se perceber a inserção ou o aumento desse tipo de produção acadêmica em diferentes regiões do país (universidades de Minas Gerais, do Sul do país, do Norte e Nordeste, bem como nas do Centro-Oeste), rompendo, dessa forma, com a hegemonia da região Sudeste, predominante até a década de 1990.

Para ilustrar esse trabalho foi realizado um levantamento que teve como fonte de pesquisa documentos de trabalho de pesquisadores do Núcleo
(01) FADUL, Anamaria (Ed.). Serial ficction in TV: the Latin American Telenovelas. Ficção Seriada na TV: as telenovelas latino-americanas. São Paulo: Escola de Comunicações e ArtesECA-USP, 1993. 251p.

(02) ORTIZ, Renato; BOREU, Sivia H. S.; RAMOS, José M. O. Telenovela: história e produção.

2 ed. São Paulo: Brasiliense, 1991. PAШOTTINI, Renata.

Dramaturgia de televisão. São Paulo: Modema, 1998.

MATTELART, Michele;

MATTELARD, Amand. OCamaval das Imagens: a ficção na TV. São

Paulo: Brasiliense, 1998.

BORELU; Silvia H. S; PRIOU, Gabriel(Coords.). A Deusa Ferida: por que a Rede Globo não é mais a campeã absoluta de audiência. São Paulo: Summus, 2000.

(03) FERNANDES, Ismael. Memórias da Telenovela Brasileira. São Paulo: Brasiliense, 1997.

(04) Editada pelo Curso de Gestão de Processos Comunicacionais da ECA-USPe editoras parceiras.

(05) Atualmente fazem parte dos formatos que compõem a Ficção Televisiva Seriada: a telenovela, a minissérie, a série, o seriado, a soap opera e o sitcom.

(06) Um dos bancos de consulta obrigatónia para os pesquisadores desse temaéo da Capes no endereço eletrônico: <http:/l capes.gov.br/capes/portal/ conteudo/10/

Teses_Dissertacoes.htm. >. 
(07) Prática de refazer antigas telenovelas, adequando-se às exigências dos tempos atuais. $A$ partir da década de 1990, essa prática foi intensificada pelas diferentes emissoras de TV brasileira.

(08) Horário vespertino inaugurado pela Rede Globo para reprise das telenovelas, na maioria das vezes, das telenovelas do horário. Em muitos momentos essas reprises alcançam maior audiência do que as alcançadas em suas primeiras exibições. Acontece também a veiculação de reprises. de Pesquisa de Telenovela - NPTN da ECA-USP, intitulado "Produção Acadêmica no Brasil sobre Ficção Televisiva Seriada Brasileira", os bancos de dados do CNPq, da CAPES, do NUPEM, das bibliotecas da USP e da PUC-SP. Nessa varredura encontraram-se 126 trabalhos compreendidos entre os anos de 1970 a 2000, o que pode ser verificado no Gráfico 1 .

Cabe destacar que no período de 1990 a 1995, uma das teses é de LivreDocência e outras duas também são defendidas no período de 1996 a 2000 (vide gráfico 2 na página ao lado).

Através desses gráficos pode ser observado o aumento da produção acadêmica principalmente a partir dos anos 90 . O volume tímido de produção dos anos 70 e 80 , que totaliza em duas décadas 28 trabalhos, dá um salto nos dois períodos seguintes, perfazendo um total de 98 trabalhos. Seria interessante apontar que ao tomar impulso essa produção se diversifica variando suas temáticas, como pode ser constatado no gráfico 3.

Apesar dessa diversificação de temas é necessário ressaltar que apesar das categorias não serem excludentes e tão pouco conclusivas, dos 126 trabalhos identificados no levantamento, boa parte volta-se para os estudos de recepção e cotidiano e cultura. Percebe-se um distanciamento considerável dos demais temas.

Apesar da importância dos temas de maior emergência, outros temas se perdem dado a inúmeras possibilidades que esse objeto propicia. Para justificar essa afirmação propõe-se, a título de exemplificação, algumas possibilidades de estudos: análise de outros produtos da ficção televisiva (como, por exemplo, minissérie, seriado). Ao escolher esses temas como objeto de estudo, as pesquisas prendem-se, geralmente, na investigação da transposição da obra literária para obras de televisão, visto que são muitas as minisséries e seriados que têm como base essa já consagrada linguagem. Apesar de não ter expressiva participação na grade de programação brasileira, desde 1995 ,
Malhação tem sido, uma constante na grade de programação televisiva, apresentando-se como um excelente terreno para investigação do gênero soap opera, que tem poucos trabalhos. O sitcom, resgatado a cada dia com mais freqüência pela televisão brasileira, tem também pouca atenção dos estudiosos.

Voltando à telenovela não são freqüentes os estudos que se dedicam às demais obras que são veiculadas fora do horário nobre e mesmo fora do circuito da emissora líder de audiência. $\mathrm{E}$, ainda, não existem, pelo menos no universo mapeado, pesquisas a respeito de uma das estratégias da televisão aberta brasileira: os remakes ${ }^{7}$, e mesmo os fenômenos das obras retransmitidas no Vale a Pena Ver de $\mathrm{Novo}^{8}$ da Rede Globo.

São raras, ainda, as investigações que têm o foco centrado no papel desse gênero na constituição da televisão brasileira. Embora em muitos trabalhos seja eleita como objeto central, a telenovela é utilizada como pré-texto para elucidação de questões "mais relevantes" e em vários momentos é considerada apenas como pano de fundo para reflexões sociais, políticas, culturais, deixando de fora a dimensão televisiva. Nada contra, já que a telenovela como produção cultural, evidentemente, é um excelente objeto para apreciação dessa cultura. No entanto, não se pode esquecer que ela é um produto em si que possibilita inúmeras descobertas a partir dos estudos dos elementos que a constitui.

Pouco se estuda sobre suas trilhas sonoras, interpretação de seus atores, questões de direção, de autoria, de cenografia e dos produtos gerados a partir dessas obras. $\mathrm{O}$ que ela representa como produto de exportação e consumo interno? O que isso representa para o balanço das emissoras? Só há bem pouco tempo os gastos com sua produção tornaramse mais divulgados, mas pouco se sabe quanto esse produto representa no balanço dessa empresas e mesmo na receita do país.

No Brasil, provavelmente, já foram 
Gráfico 1 - Produção Acadêmica - Ficção Televisiva Seriada Brasileira

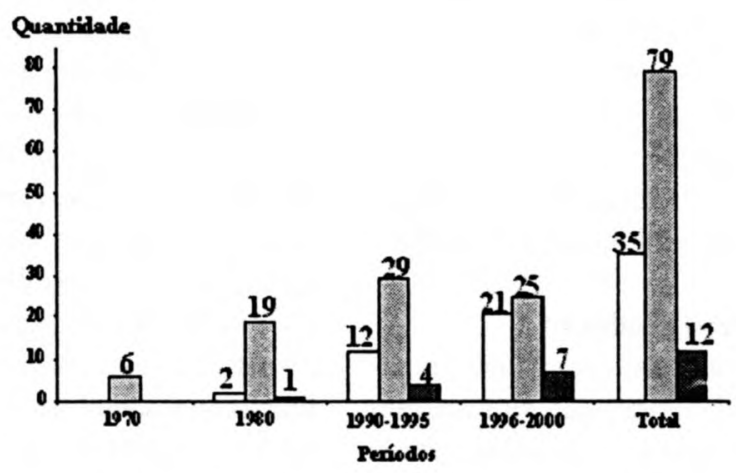

$\square$ Teses $\square$ Dissertaçöes $\mathbf{T C C}$

Gráfico 2 - Total da Produção Acadêmica:

Ficção Televisiva Seriada Brasileira

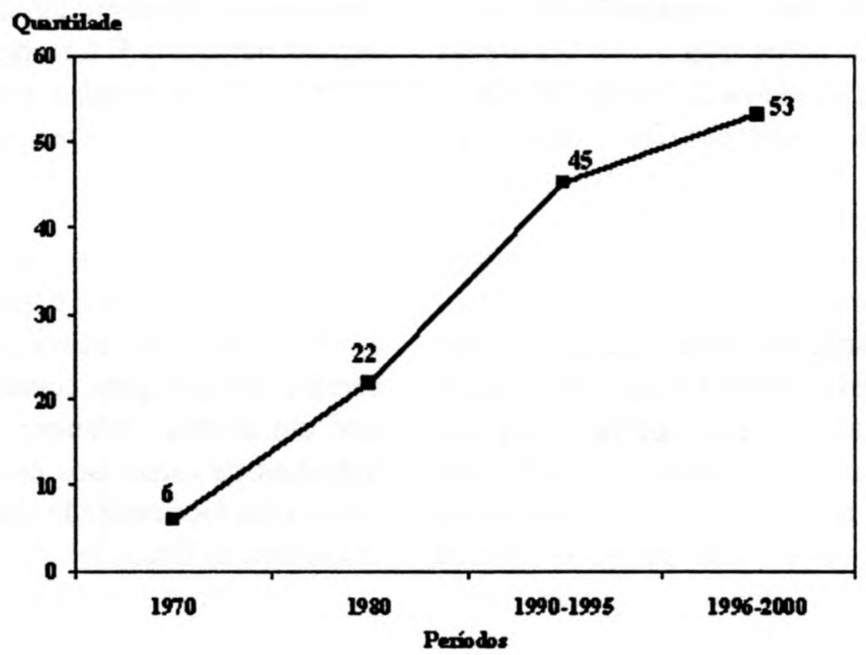

Gráfico 3 - Produção Acadêmica

Ficção Televisiva Seriada Brasileira Temas de Maior Incidência

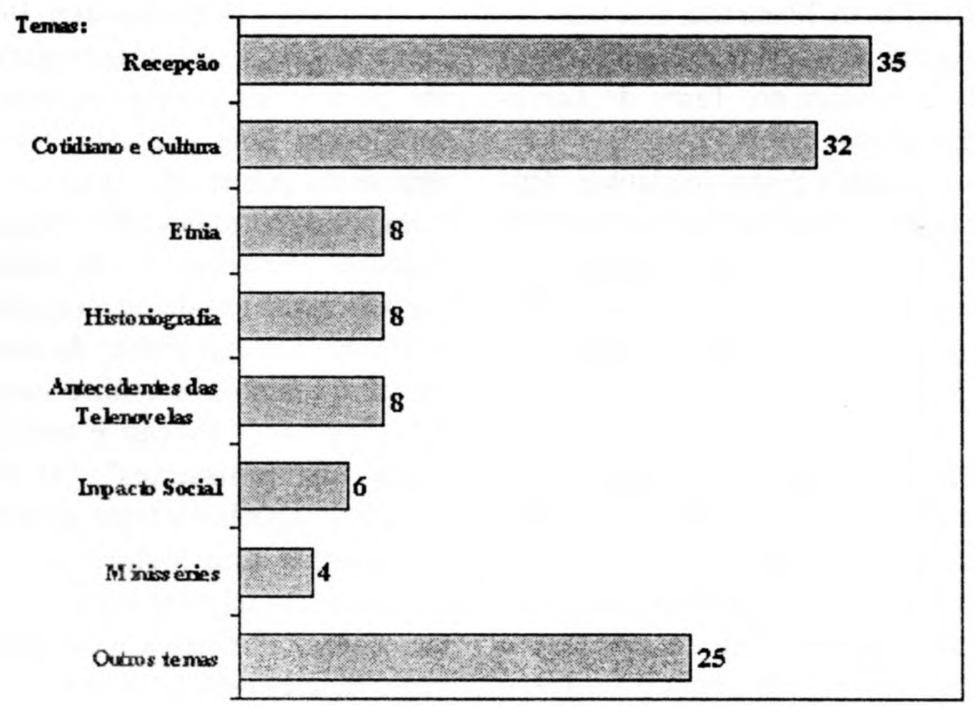


(09) Esse Núcleo de pesquisa da Intercom foi implantado por pesquisadores do NPTN da ECAUSP e durante todos esses anos tem sido coordenado por pesquisadores ligados a esse Núcleo.

(10) Para levantamento dessa produção deve-se consultaro Catálogo do grupo de trabalho ficção televisiva seriada: cinco anos de história e produção(1993 a 1997). São Paulo: Intercom/ CCA, 1997. 96p. Publicação coordenada por Maria Aparecida Baccega com resumos dos trabalhos, incluindo análise dessa produção realizada por Maria Lourdes Motter, a partir do levantamento e organização de 77 artigos acadêmicos, apresentados nos Grupos de Trabalho da Intercom ao longo dos anos citados. Para contato com a produção posterior a essa publicação énecessánio consultar os anais desses Congressos que, a partir de 1999, tem utilizado como suporte para essas produções, além do material impresso, CD-Rom. vinculadas mais de 700 obras de ficção televisiva, de produção nacional ou estrangeira, desde seu ingresso nas telas em 1951. Com certeza há muito que se investigar sobre esse produto ficcional. Já temos significativas mudanças no panorama da produção acadêmica, mas há muito a ser feito.

\section{Contribuições à produção}

É oportuno salientar duas iniciativas sitematizadoras que se tomaram também referências para quem estuda ficção televisiva.

Como foi demonstrado nos gráficos, a produção toma impulso nos anos 1990. Algumas iniciativas, dentre outras, podem ser apontadas como incentivo para a construção do campo de estudo sobre telenovelas brasileiras e outros formatos da Ficção Televisiva Seriada. A primeira foi a criação do Núcleo de Pesquisa de Telenovela NPTN na Escola de Comunicações e Artes da USP, em 1992, que se constitui como primeiro centro do Brasil destinado exclusivamente à pesquisa sobre telenovela, dando suporte a pesquisas nacionais e estrangeiras. Em um levantamento rápido poderá ser percebida a atuação desse centro como fomentadador das pesquisas nessa década. Ao longo desses dez anos o NPTN, reunindo alunos de pósgraduação, produziu pesquisas com orientação direta das professoras ligadas ao Núcleo. Em uma década de existência foram produzidas sete dissertações de Mestrado, sete teses de Doutorado, além de duas pesquisas que se desdobraram em Teses de LivreDocência (vide tabela 1).

A segunda destas iniciativas deuse no Congresso da Sociedade Brasileira para Estudos Interdisciplinares da Comunicação - Intercom, em 1993, quando se organizou, pela primeira vez, um Grupo de Trabalho (GT), que teve como tema a telenovela. Nesse momento de criação, denominou-se GT de Telenovela. Esse Grupo de Trabalho teve como meta socializar o conhecimento sobre ficção televisiva, tomandose assim um fórum de debates e intercâmbio entre pesquisadores e estudiosos da área. Esse espaço caracterizou-se, desde sua criação, como um canal de legitimação dos estudos sobre ficção televisiva. O Núcleo de Ficção Seriada, denominação atual, é hoje, dentro da Intercom, um dos que registra maior número de expositores e participantes. Analisando o percurso de desenvolvimento desse NT, é possível perceber modificações significativas, mudanças essas que funcionam como um dos sinalizadores para configuração dos estudos sobre esse tema no Brasil ${ }^{9}$.

No início, esse Núcleo da Intercom contava com trabalhos apresentados por expositores estrangeiros, que utilizavam como objeto de análise produtos ficcionais predominantemente latino-americanos. É somente a partir de 1995 que esse quadro começa a se inverter, com a presença de expositores dos trabalhos, na sua maioria, brasileiros.

No ano de 2001, esse Núcleo totalizou cento e trinta e quatro artigos apresentados por pesquisadores de várias regiões do país, contanto, mesmo que em número menor, ainda com trabalhos de estudiosos estrangeiros ${ }^{10}$, mas já com foco centrado nas produções brasileiras de ficção televisiva.

Além disso, os resultados dessas inúmeras pesquisas têm sido alvo do interesse de editoras, o que proporciona um aumento considerável na publicação de obras sobre a Ficção Televisiva Seriada.

Da estréia na academia em 1974 aos dias atuais pode-se constatar que a cada ano os estudos sobre esses objetos se fortalecem. Isso pode ser verificado através da publicação de obras como: "Dramaturgia de televisão"; "Querência cultural regional como mediação simbólica: um estudo de recepção"; "A milésima segunda noite: da narrativa mítica à telenovela análise estética e sociológica"; "Ficção e política: o Brasil nas minisséries"; "O fim do mundo: imaginário e teledramaturgia"; "Eu compro essa mulher: romance e consumo nas telenovelas brasileiras e mexicanas"; "A negação do Brasil: o negro na telenovela brasileira"; "O autor 
Tabela 1: Dissertações e Teses NPTN (Período: 1992-2002)

\begin{tabular}{|c|c|c|c|}
\hline Autor & Título & Titulação & Titulação \\
\hline AGUIEIRO, Gabriela Hasimoto & Ficção televisiva e política: a obra de Dias Gomes & Mestrado & 2001 \\
\hline ARAÚJO, Joel Zito de A. & $\begin{array}{l}\text { A negação do Brasil. Identidade racial e estereótipos } \\
\text { sobre o negro na história da telenovela brasileira }\end{array}$ & Doutorado & 1999 \\
\hline BARBOSA, Luciene C. & $\begin{array}{l}\text { Louca Paixão: questões raciais na telenovela sob o } \\
\text { olhar do receptor }\end{array}$ & Mestrado & 2002 \\
\hline BARROS JR, Rui C. & $\begin{array}{l}\text { Temáticas sociais em telenovelas e cultura popular } \\
\text { cuiabana: uma questão de negociação de sentidos }\end{array}$ & Doutorado & 2000 \\
\hline BONIN, Jiani Adriana & Identidade étnica, cotidiano familiar e telenovela, & Doutorado & 2001 \\
\hline CASTRO-POZO, Tristán D. C. & $\begin{array}{l}\text { Os novatos e o teste de elenco nas redes de televisão: } \\
\text { um estudo comparativo entre o Centro de Educación } \\
\text { Artística da Cadena Televisa e a Oficina de Atores da } \\
\text { Rede Globo }\end{array}$ & Mestrado & 2000 \\
\hline COSTA. Maria C. C. & $\begin{array}{l}\text { A milésima segunda noite: da narrativa mítica à } \\
\text { telenovela. Estudo estético e sociológico }\end{array}$ & Livre-Docência & 1998 \\
\hline COSTA, Robson B. & Autoria ficcional: a telenovela de Silvio de Abreu & Mestrado & 1998 \\
\hline GENTILLI, Irene R. & $\begin{array}{l}\text { A expressão não-verbal do discurso verbal em Terra } \\
\text { Nostra: Raul Cortez e as múltiplas faces de Francesco, }\end{array}$ & Mestrado & 2002 \\
\hline HARTMANN, Atílio I. & $\begin{array}{l}\text { Religiosidade e Mídia Eletrônica: a mediação } \\
\text { sociocultural religiosa e a produção de sentido na } \\
\text { recepção de televisão }\end{array}$ & Doutorado & 2000 \\
\hline LOBO, Narciso J. F. & Ficção e política: o Brasil nas minisséries & Doutorado & 1997 \\
\hline MALCHER, Maria A. & $\begin{array}{l}\text { A legitimação da telenovela e o gerenciamento de sua } \\
\text { memória: o Núcleo de Pesquisa de Telenovela da } \\
\text { ECA-USP }\end{array}$ & Mestrado & 2001 \\
\hline MOTTER, Maria L. & Ficção e Realidade: a construção do cotidiano & Livre-Docêncica & 1999 \\
\hline OLIVEIRA, Mônica de M. & Telenovela e Romance: Tocaia Grande na sala de aula & Mestrado & 1997 \\
\hline OROFINO, Isabel M. & $\begin{array}{l}\text { Mediações na produção de teleficção: videotecnologia } \\
\text { e reflexividade na microssérie O Auto da Compadecida }\end{array}$ & Doutorado & 2001 \\
\hline TORRES MORALES, Ofélia E. & $\begin{array}{l}\text { Nos bastidores da telenovela: a produção do noticiário } \\
\text { sobre a telenovela O Rei do Gado na revista Contigo! }\end{array}$ & Doutorado & 1999 \\
\hline
\end{tabular}


(11) PALLOTTINI, Renata. Dramaturgia de Televisão. São Paulo: Modema, 1998. 207p. JACKS, Nilda. Querência cultural regional como mediação simbólica: um estudo de recepção. Porto Alegre: Ed. Universidade-UFRS, 1999. 286p. COSTA, Maria C. C. A milésima segunda noite: da narrativa mítica à telenovela análise estética e sociológica. São Paulo: Annablume, 2000. 228p. LOBO, Narciso J. F. Ficção e política: 0 Brasil nas minisséries. Manaus: Valer, 2000. 352p. ANDRADE, Roberta M. B. Ofim do mundo: imaginánio e teledramaturgia. São Paulo: Annablume, 2000. 126p. COSTA, Cristiane Eu compro essa mulher: romance e consumo nas telenovelas brasileirase mexicanas. Rio de Janeiro: Jorge Zahar, 2000. 132p. ARAÚJO, Joel Zito de A. A negação do Brasil: o negro na telenovela brasileira. São Paulo: SENAC, 2000. 323p. NOGUERA, Lisandro. Oautorna televisão. Goiânia: Ed. da UFG; São Paulo: EDUSP, 2002 FOGOLARI, Élide Maria. O visível e o invisível no ver e no olhara telenovela: recepção, mediaçãoe imagem. São Paulo: Paulinas, 2002. LEITE, Adriana. Figurino: uma experiência na televisão. São Paulo: Paz e Terra, 2002 236p. ALENCAR, Mauro. A Hollywood Brasileira: panorama da telenovela no Brasil. Rio de Janeiro: Senac, 2002 175p. (12) BOURDIEU, Pierre. O Campo científico. In: ORTIZ, Renato. (Org.). Pieme Bourdieu. São Paulo: Ática, 1983, p. 122 na televisão; $\mathrm{O}$ visível e o invisível no ver e no olhar a telenovela: recepção, mediação e imagem"; "Figurino: uma experiência na televisão"; "A Hollywood Brasileira: panorama da telenovela no Brasill". A citação destas obras é apenas uma forma de ilustrar as afirmações deste trabalho, não tendo, desse modo, intenção de fazer uma cobertura completa de todas as publicações desta área11.

Não se deve deixar de mencionar que esse interesse tem como uma de suas variáveis o marco de comemoração dos cinqüenta anos de televisão do Brasil em 2000, mas não só, pois geralmente o alvo das editoras volta-se para produtos de apelo mais mercadológico e os trabalhos acadêmicos não despertam grande interesse, já que não são artigos para grandes vendas. Sendo assim, é possível considerar como aspecto favorável, que a Academia produziu, ao longo dessas décadas, trabalhos que atraíram o olhar dos que ditam as normas da produção editorial.

\section{Considerações Finais}

Todo processo de construção do conhecimento em uma área de estudo envolve pessoas, recursos (intelectuais e materiais) e políticas de vários agentes financiadores. Essa construção não está restrita aos limites físicos do lugar onde acontece, e sim, envolta numa rede que forma uma teia complexa de relações tecidas a partir das necessidades do fazer científico de cada projeto de pesquisa. O universo "puro" da mais "pura" ciência é um campo social como outro qualquer, com suas relações de força e monopólios, suas lutas e estratégias, seus interesses e lucros, mas onde todas essas invariantes revestem formas específicas ${ }^{12}$.

Acredita-se que os apontamentos aqui registrados possam auxiliar aos pesquisadores, que elegem a ficção televisiva como alvo de suas preocupações acadêmicas. $\mathrm{O}$ esgotamento das possibilidades de investigação não se deu e provavelmente nunca se dará, pois como produto cultural inserido no campo da comunicação a telenovela e os demais produtos da ficção televisiva acompanham a dinâmica da sociedade e por ser dinâmica é também complexa e mutável. Não se conclui neste artigo o levantamento da produção dessa área, no entanto, acredita-se que o apresentado seja o início, favorecendo o aprofündamento desse trabalho por esta e demais pesquisadores.

Além disso, espera-se que tenha sido possível perceber a possibilidade de novos caminhos de investigação bem como a necessidade constante de consulta ao capital científico produzido sobre o tema. Pois não se inventa a roda a todo instante e é nesse constante repensar e questionar que se dá o desenvolvimento das ciências. Desconsiderar o que já se produziu é confinar os estudos a objetivos distantes dos da academia é inviabilizar o crescimento da área. 


\section{Referências Bibliográficas}

BACCEGA, Maria A. (Coord.). Catálogo do grupo de trabalho ficção televisiva seriada: cinco anos de produção de textos críticos (1993/1997). São Paulo, CCA/ECA/Intercom/ NPTN, 1997.

BOURDIEU, Pierre. O Campo científico. In: ORTIZ, Renato. (Org.). Pierre Bourdieu. São Paulo: Ática, 1983.

. Razões práticas: sobre a teoria de ação. São Paulo: Papirus, 1996.

CHRÉTIEN, C. A ciência em ação. São Paulo: Papirus, 1994.

FADUL, Anamaria (Ed.). Serial ficction in TV: the Latin American Telenovelas. Ficção Seriada na TV: as telenovelas latino-americanas. São Paulo: ECA-USP, 1993.

ISMAEL, Fernandes. Memória da telenovela brasileira. 4. ed. ampl. São Paulo: Brasiliense, 1997.

LIMA, Solange M. C. de.; MOTTER, Maria L.; MALCHER, Maria A. A telenovela e o Brasil: relatos de uma experiência acadêmica. Intercom. São Paulo, v. XXIII, n. 1, jan./jun.2000.

MALCHER, Maria A. A Legitimação da Telenovela e o Gerenciamento de sua Memória: o Núcleo de Pesquisa de Telenovela da ECA-USP. São Paulo, 2001. 385p. Dissertação de Mestrado (Ciência da Comunicação) - Escola de Comunicações e Artes, Universidade de São Paulo. Manaus. 2000.

A Telenovela como objeto científico. In: Anais do XXIII Intercom,

MORIN, Edgar. A cabeça bem feita: repensar a reforma, reformar o pensamento. Rio de Janeiro: Bertrand Brasil, 2000. 